\title{
Synchronized Measurement based an Adaptive distance relaying Scheme for STATCOM Compensated Transmission line
}

\author{
Arvind R. Singh*†, Dr. Nita R. Patne ${ }^{\ddagger}$ and Dr.Vijay S. Kale \\ *Department of Electrical, Electronics and Computer Engineering, University of \\ Pretoria, South Africa \\ $\ddagger$ Department of Electrical Engineering, VNIT, Nagpur-440010, India. \\ $\dagger$ Email:arvindsinghwce@gmail.com
}

\begin{abstract}
Protection of bulk power delivering transmission line (TL) is very important for power system stability and reliability. The environmental and right of way restrictions delayed the construction of new transmission line to meet the deregulated power demands. Shunt FACTS devices connected in the transmission system enhances the power transfer capability up to its thermal limit. Shunt FACTS devices have the ability to control series impedance, shunt impedance, current, voltage and load angle. STATCOM is one of such shunt FACTS devices which severely affect the protection system installed for TL. This research work is focused on the addressing the issues with distance relaying of STATCOM compensated TL and to overcome these adverse effects, new adaptive relaying algorithm is presented based on synchronized measurement. The proposed algorithm is implemented in PSCAD EMTDC simulation to validate its performance in terms of accuracy and reliability subjected to various faults on TL. Error in the fault location estimation with proposed algorithm is $0.6 \%$ for $300 \mathrm{~km}$ TL. To claim the superiority and its accuracy, the algorithm is tested in hardware environment with faults in offline mode.
\end{abstract}

Key words: Adaptive Distance Relaying, Synchronized Measurement, STATCOM, Shunt Compensation.

\section{Introduction}

Wide Area Measurement Systems (WAMs) is one of the most significant new developments in modern power systems. Through the developments in synchronized measurement technology and the creation of phasor measurement 
units (PMUs) [1], WAM is able to offer a real time view of the dynamic behavior of a power system. WAM is the base for all new digital relaying algorithms and offers many opportunities to improve the performance of power system in the field of protection. This work presents one of such opportunity and motivation for the development of adaptive relaying scheme based on synchronized measurement. This method includes measurement and monitoring the suitability of the relay performance. Wide area measurements enhanced capability is already leading to an increasing amount of intelligence in power system controllability and decision making. Application of this new measurement technology is now moving from the control center to the substation. The new protection algorithm discussed here is an application of synchronized measurement. WAM collects measurements from remote locations in the power system and combines them in real time into a single snapshot of the real system parameters for the given time. Synchronized measurement is an essential component of WAMs, as it allows measurements to be time stamped accurately using time signals from Global Positioning System (GPS). These time stamps allow the measurements to be combined easily and also allow phase angle measurements using a common reference.

WAMs offer a wide variety of opportunities for enhancing the backup protection and system protection in modern power systems. These enhancements can contribute to lessen the mal-operation of backup relays, limit the impact of hidden failures and create new tools for managing wide area disturbances. These benefits indicate that the main role of wide area measurement as part of protection is improving the resilience of power systems against stressed conditions and wide area disturbances not just the isolation of individual faults. The deployment of these well considered concepts should reduce the frequency and intensity of blackouts and enable more rapid service restoration.

Transmission line protection is very important aspect for power system stability and secure operation of power. Long high voltage lines are mostly used as power corridor to transfer large volume of power from generating stations to loading station. Distance relay based transmission line protective relaying provides information of faults fall in the protected zone [1]. Increasing power demand in the energy sector, environmental hurdles and right of way curtail the building of new transmission line which forced the utilities for optimal utilization of transmission line to its thermal limit. To enhance the power transfer capability, Flexible AC Transmission System (FACTS) devices were introduced $[2,3]$. These devices have ability to modify the line impedance, load angle, voltage and current of the system by controlling the reactive power injection [4-6]. These FACTS devices either connected in series / shunt or both. These devices have fast response which overlapped with protection system response time leading to mal operation of relaying devices connected in the system [7].

The most widely used protection device for transmission line is distance relay which is more reliable and incorporable [8]. The relaying devices mal function to locate the faults accurately when shunt compensation is present on line [9]. 
The distance relays are mostly employed for protection of such important lines. The detailed literature survey for performance of distance relay is conducted considering the effects of Static Synchronous Compensator (STATCOM) operating characteristics, control strategy and response with various faults. With presence of shunt compensation, distance relaying scheme mal-function to detect and locate faults in correct protective zones because of under-reaching/ over-reaching fault points [10-13]. For fault before STATCOM point of installation, it not comes in the fault loop and effect of injected compensation in the fault current is very less. For fault after the mid-point, STATCOM included in fault loop and injected compensation has significant effect in fault current which lead to severe problems in protection system.

The latest literature suggests use of WAMs based new methodologies for primary and back-up protection [14, 15]. New algorithms based on synchronized measurement at two ends, application of PMUs and various pilot protection schemes using communication link have been proposed to diminish the problems in distance protection due to shunt compensation [16-18],[20-25]. To solve these problems, Communication aided based distance relay schemes with blocking algorithm to mitigate the effect of compensating devices are presented in [9]-[13]. The authors in [6], have pointed to increase the reach of zone setting with the maximum reach point for inductive and capacitive compensation. But analytical justification was not provided for intermediate level of compensation and also steady state equation depicted are helpful for finding impedance characteristics during the various faults. Using synchronized measurement technique with high speed communication link to eliminate the distance relay measurement error in presence of shunt compensation was presented in[10]. In [11], channel aided communication based pilot relying for directional comparison of parameters was proposed to locate fault point using both ends measurements for the protection of $300 \mathrm{~km}$ line. The use of conventional communication methodology give rise to long trip decision time and delay in detection of faults on the transmission line.

WAMs based protection algorithms for TL protection with high speed data communication has open new area in development of new protective algorithms. WAMs based protection have synchronization error for $1 \mu \mathrm{sec}$, which contribute to $0.018^{\circ}$ in $50 \mathrm{~Hz}$ whereas $0.0216^{\circ}$ in $60 \mathrm{~Hz}$. Errors in measurements can be eliminated if data is processed with time tag at relaying point for decision making. Authors in [16], have used high speed communication topology to transfer data for $300 \mathrm{~km}$ of line to design the current deferential protection algorithm, the same technology is used to transfer information of estimated phasor measurements to the relaying bus for $150 \mathrm{~km}$ of transmission line reducing the cost of investment.

In this research work adaptive distance relay setting algorithm is revisited to mitigate the effect of shunt compensation injected by STATCOM. The distance protection response to the mid-point STATCOM on transmission line is analyzed to understand the errors in the distance protection. Then, adaptive distance protection is derived analytically to overcome the errors due to 
STATCOM. And fault analysis is carried out in simulation for various faults to verify the performance of new adaptive distance relaying algorithm. Fault analysis is performed for all types of severe faults and resistive faults considering optimum STATCOM injection. Organization of paper is as follows: brief description of study system with STATCOM is given in Section II. In Section III, analytical study is presented for conventional distance relaying with STATCOM at mid-point. Analytical study is helpful in determining errors in distance relaying. Section IV shows mathematical analysis of adaptive relaying scheme. Adaptive distance relaying model of PSCAD [19] and its algorithm with STATCOM is given in section V. Simulation results are presented for adaptive relaying in section VI. Hardware based validation is presented in the section VII followed by conclusion based on results.

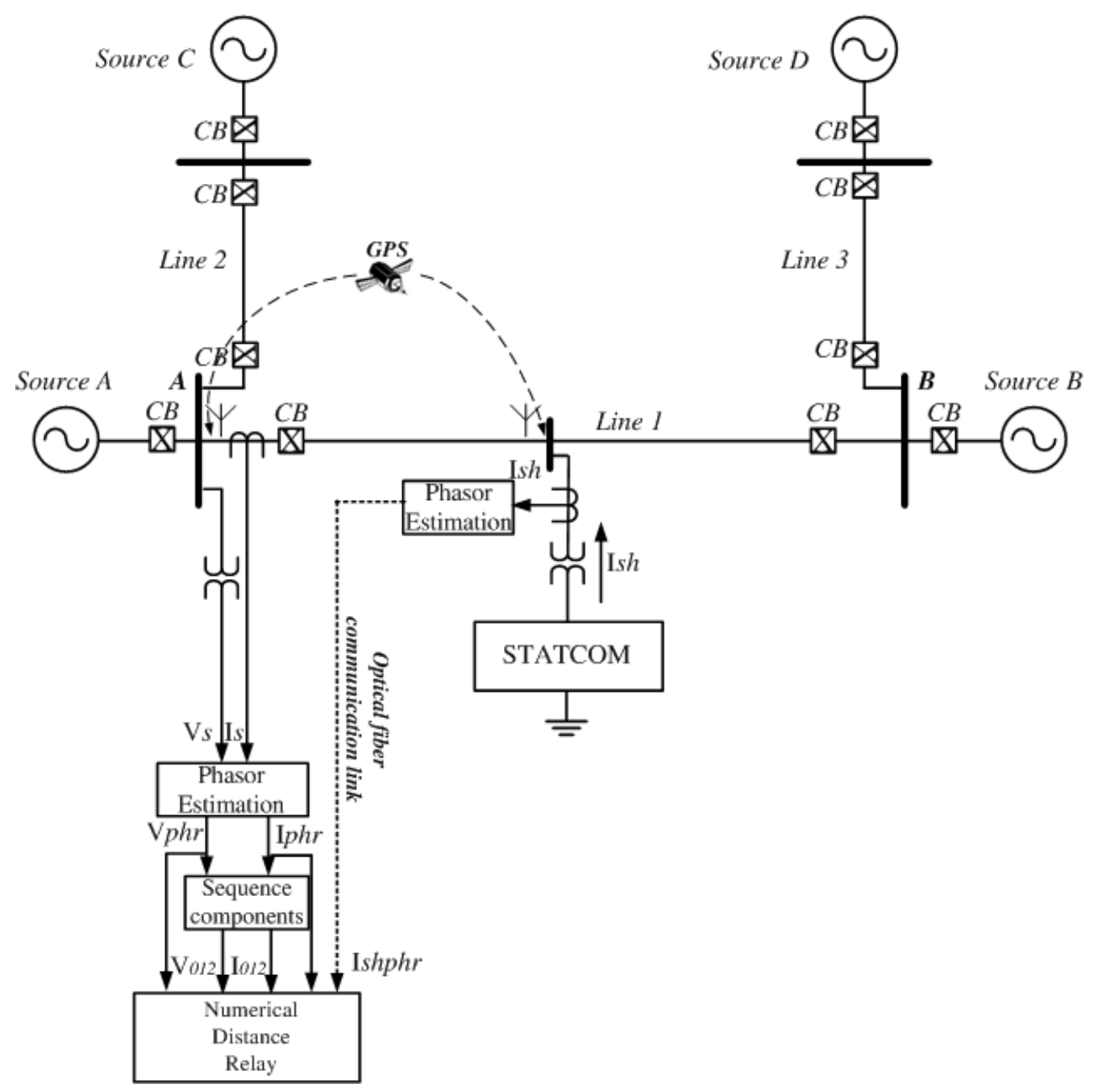

Fig. 1. Study System adaptive relaying architecture 


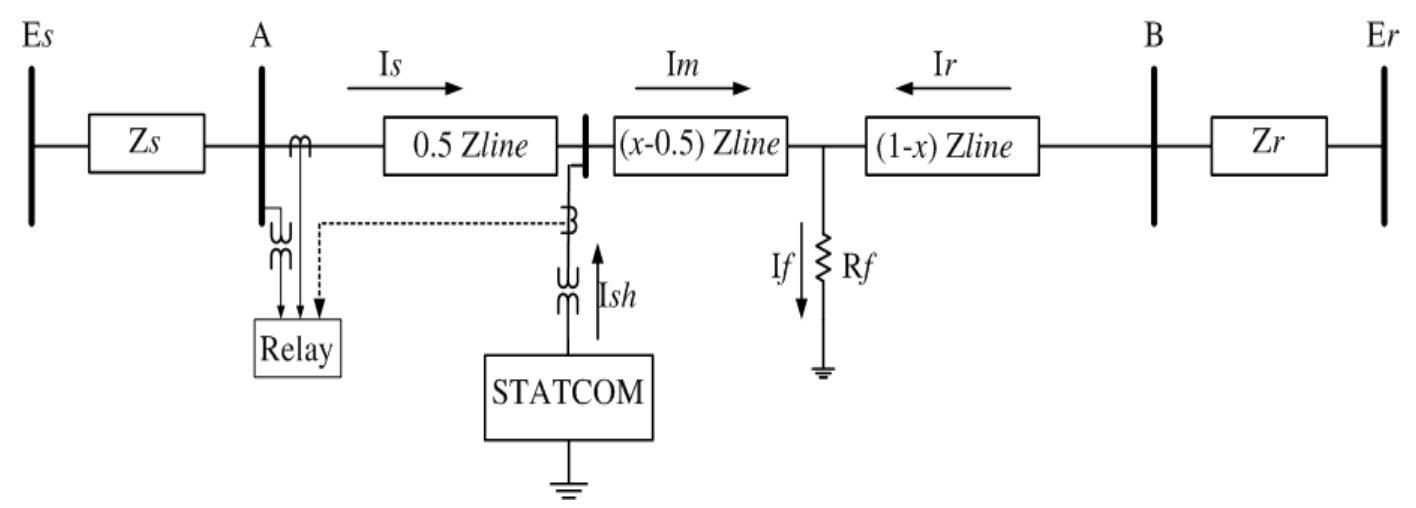

Fig. 2. Equivalent circuit for faults fault analysis

\section{$2 \quad$ Study System Modeling}

The test study system used in this study is shown in Fig. 1, for four bus power system with mid-point STATCOM. The shunt compensating device, STATCOM is connected at mid-point of the transmission line and modeled as 12-pulse voltage source converter [22]. The control system of compensating device has two modes of operation viz., voltage regulation mode and reactive power injection mode. In voltage regulation mode, compensating device maintain voltage to 1 p.u. voltage either absorbing or injecting compensation. In reactive power injection mode, the amount of reactive power need to be injected is fixed (inductive or capacitive) irrespective of connection point voltage. To study the shunt compensating device operation mode effect on fault transient signal, the later control mode is used to have control over reactive power injection into system.

\section{Calculation of Apparent Impedance}

Expression of apparent impedance for distance relay unit is installed on bus A with mid-point STATCOM is derived using Symmetrical components for faults. Voltage and current phasors are calculated using moving window Discrete Fourier Transform (DFT) [5]. The equivalent circuit of line-1 during fault in presence of STATCOM is shown in Fig. 2. For faults before the STATCOM, it is not included in the fault loop and has no impact on apparent impedance calculation. When fault occurs after the STATCOM, it is always present in the fault loop and adversely affects measured apparent impedance. 


\subsection{For line to ground fault}

$$
\begin{aligned}
& V_{s 1}=0.5 I_{s 1} Z_{\text {line } 1}+I_{m 1}(x-0.5) Z_{\text {line } 1}+R_{f} I_{f 1} \\
& V_{s 2}=0.5 I_{s 2} Z_{\text {line } 1}+I_{m 2}(x-0.5) Z_{\text {line } 1}+R_{f} I_{f 2}
\end{aligned}
$$

$\left[\right.$ Since $\left.Z_{\text {line2 } 2}=Z_{\text {line1 } 1}\right]$

$$
\begin{aligned}
& V_{s 0}=0.5 I_{s 0} Z_{\text {line } 0}+I_{m 0}(x-0.5) Z_{\text {line } 0}+R_{f} I_{f 0} \\
& I_{m 1}=I_{s 1}+I_{s h 1} \\
& I_{m 2}=I_{s 2}+I_{s h 2} \\
& I_{m 0}=I_{s 0}+I_{s h 0}
\end{aligned}
$$

Where,

$V_{s 1}, V_{s 2}, V_{s 0}, I_{s 1}, I_{s 2}$ and $I_{s 0}$ are voltage \& current sequence components.

$Z_{\text {line } 1}, Z_{\text {line } 2}$ and $Z_{\text {line } 0}$ are TL impedance sequence components.

$I_{f 0}, I_{f 1}$ and $I_{f 2}$ are fault current sequence component.

$I_{s h 0}, I_{s h 1}$ and $I_{s h 2}$ are injected compensation current sequence components. $x$ per unit distance.

Voltage at bus-A is $V_{s a}$ as:

$$
V_{s a}=V_{s 1}+V_{s 2}+V_{s 0}
$$

Substituting the values of equation (1) to (6) in equation (7), expanding inside brackets for recalculation, we get-

$$
\begin{aligned}
V_{s a}= & x I_{s 1} Z_{\text {line } 1}+x I_{\text {sh } 1} Z_{\text {line } 1}-0.5 Z_{\text {line } 1} I_{\text {sh } 1} \\
& +R_{f} I_{f 1} x I_{s 2} Z_{\text {line } 1}+x I_{\text {sh } 2} Z_{\text {line } 1} \\
& -0.5 Z_{\text {line } 1} I_{\text {sh } 2}+R_{f} I_{f 2} x I_{s 0} Z_{\text {line } 0}+x I_{\text {sh } 0} Z_{\text {line } 0} \\
& -0.5 Z_{\text {line } 0} I_{\text {sh } 0}+R_{f} I_{f 0}
\end{aligned}
$$

Adding and subtracting $\left(x I_{s 0} Z_{\text {line } 1}\right),\left(x I_{\text {sh } 0} Z_{\text {line } 1}\right)$ and $\left(0.5 I_{s 0} Z_{\text {line } 1}\right)$ in equation (8):

$$
\begin{aligned}
V_{s a}= & x I_{s a} Z_{\text {line } 1}+\left[(x-0.5)\left(Z_{\text {line } 0}-Z_{\text {line } 1}\right)\right. \\
& \left.\left.I_{\text {sha }}+I_{s h 0}\right)+x I_{s 0}\left(Z_{\text {line } 0}-Z_{\text {line } 1}\right)\right] \\
& +R_{f} I_{f a}
\end{aligned}
$$


Considering $R_{f}=0$, to remove the effect of fault resistance, the last term of equation (9) can be eliminated. As distance relay Mho characteristic is especially used for severe faults, they have low fault resistances. Hence, to make mathematical derivation simple for calculation of adaptive distance relay setting, $R_{f}=0$ is assumed. Adaptive distance protection setting calculation will be used to realize Mho characteristics. It will adapt the changes due to shunt compensation and inherent properties of distance relay. The zero-sequence current due to STATCOM $\left(I_{s h 0}\right)$ is eliminated considering delta connection type at secondary side of coupling transformer. Applying these changes, equation (9) rewritten as,

$$
\begin{aligned}
V_{s a}= & x I_{\text {sa }} Z_{\text {line } 1}+\left[( x - 0 . 5 ) \left(Z_{\text {line } 0}\right.\right. \\
& \left.\left.-Z_{\text {line } 1}\right) I_{\text {sha }}+x I_{s 0}\left(Z_{\text {line } 0}-Z_{\text {line } 1}\right)\right]
\end{aligned}
$$

Phase-A ground element calculate apparent impedance as,

$$
Z_{a p p}=\frac{V_{s a}}{I_{s a}+m I_{s 0}}
$$

where, $m=\frac{Z_{\text {line0 }}-Z_{\text {line1 }}}{Z_{\text {linel }}}$

Substituting, $V_{s a}$ in (11) and simplifying we get,

$$
Z_{\text {app }}=\underbrace{x Z_{\text {line1 }}}+\underbrace{\frac{(x-0.5) I_{\text {sha }} Z_{\text {line1 } 1}}{I_{s a}+m I_{s 0}}}
$$

\subsection{For LLL fault}

For LLL fault, the apparent impedance can be calculated considering similar assumptions made while deriving for SLG fault. The expression after simplification is given as,

$$
Z_{\text {app }}=x Z_{\text {line } 1}+\frac{(x-0.5) I_{s h} Z_{\text {line } 1}}{I_{s}+m I_{s 0}}
$$

It is evident from equation (12) and (13) that, error is present in apparent dependence calculation due to mid-point shunt compensation injected current for SLG and LLL faults. Similarly, the effect of compensation is present in all other faults. The presence of zero sequence component in equation (13) is obtained after simplification and for the cases of phase to phase faults are considered, zero sequence component is zero or very negligible and mostly not shown in the equation. But as equation is obtained after simplification and required for derivation of adaptive distance protection for all types of fault hence, it shown in the equation. 


\section{Adaptive Distance Protection Derivation}

It is clear from equation (12) and (13), the shunt injected current by STAT$\mathrm{COM}$, introduces error in apparent impedance calculation. It is assumed that GPS time stamping is present at bus-A and at compensator bus having optical fiber data transfer capability [20]-[25]. With time stamped GPS synchronized measurement and dedicated optical fiber data transfer system, the information of $\left(I_{s h}\right)$ is made available at bus-A without any transfer delay. To mitigate the mal-operation of distance relay, the modification is required in the apparent impedance calculation adaptively.

The adaptive distance protection setting can be calculated for each element of distance relay considering each phase separately. To make it simple further mathematical synthesis is performed on LLL apparent impedance equation (13). Also, confusion due to phase subscript ( $\mathrm{a}, \mathrm{b} \& \mathrm{c}$ ) for each phase is resolved making it easy to understand. Comparing apparent impedance calculated for faults in equation (12) with setting impedance $\left(Z_{\text {set }}\right)$. Also, calculated apparent impedance is equal to first zone distance relay setting, to derive the expression for adaptive distance protection as:

$$
Z_{\text {app }}=Z_{\text {set }}=0.8 Z_{\text {line } 1}
$$

Comparing equation (13) and (14),

$$
\begin{aligned}
& 0.8 Z_{\text {line } 1}=x Z_{\text {line } 1}+\frac{(x-0.5) I_{s h} Z_{\text {line } 1}}{I_{s}+m I_{s 0}} \\
& 0.8=x+(x-0.5) \frac{I_{s h}}{I_{s}+m I_{s 0}}
\end{aligned}
$$

Let $x=(\varphi+0.5)$, substituting in (16)

$$
\begin{aligned}
& 0.8=(\varphi+0.5)+\varphi \frac{I_{s h}}{I_{s}+m I_{s 0}} \\
& \varphi\left(1+\frac{I_{s h}}{I_{s}+m I_{s 0}}\right)=0.3 \\
& \varphi=\frac{0.3}{\left(1+\frac{I_{s h}}{I_{s}+m I_{s 0}}\right)}
\end{aligned}
$$

Putting $\varphi=(x-0.5)$ in (19) we get,

$$
x=0.5+\frac{0.3}{\left(1+\frac{I_{s h}}{I_{s}+m I_{s 0}}\right)}
$$


The factor $x$, is per unit fault distance as assumed previously. But, during the derivation, we have neglected the fault current and resistance from the apparent impedance calculation formula. Also, calculated apparent impedance in presence of STATCOM is compared with first zone setting of distance relay. Hence, factor $x$, now defines the adaptive reach setting with STATCOM is as observed from the equation (20). To eliminated adaptive setting factor $x$ and to get adaptive distance protection setting in presence of STATCOM, $x$ is multiplied with $Z_{\text {line1 }}$.

$$
Z_{\text {setnew }}=x Z_{\text {line } 1}
$$

Substituting the value of $x$ in (21), we get

$$
Z_{\text {setnew }}=\left(0.5+\frac{0.3}{\left(1+\frac{I_{s h}}{I_{s}+m I_{s 0}}\right)}\right) Z_{\text {line } 1}
$$

Following conclusion are made from equation (22) as:

- Adaptive distance protection equation derived is considered for mid-point compensated line only.

- Shunt injected current by STATCOM introduces error in the apparent impedance calculation.

- Adaptive distance protection equation effectively defines the new reach setting considering the injected current by STATCOM.

- The new first zone setting effectively accommodates the nature of injected current for both operating mode of STATCOM .

- When current injected by STATCOM is capacitive, $I_{s h}$ is considered as positive then adaptive distance protection reach setting will be increased.

- And, if current injected by STATCOM is inductive, $I_{s h}$ is considered as negative then adaptive distance protection reach setting will decreased.

\section{Adaptive distance relaying and its algorithm}

Adaptive distance protection derivation shown in previous section is implemented in EMTDC PSCAD environment as shown in Fig. 3. PSCAD simulation clock is considered as GPS time stamp. It is assumed that, fast data communication channel is available between two measurement points. The instantaneous values of relaying bus voltage and current obtained from measuring instruments are processed to extract phasors using DFT. Similarly, shunt injected current obtained from measuring instruments is also processed to calculate phasors. The extracted phasors of injected current are received at relaying bus. The relaying bus current phasor with sequence component and 


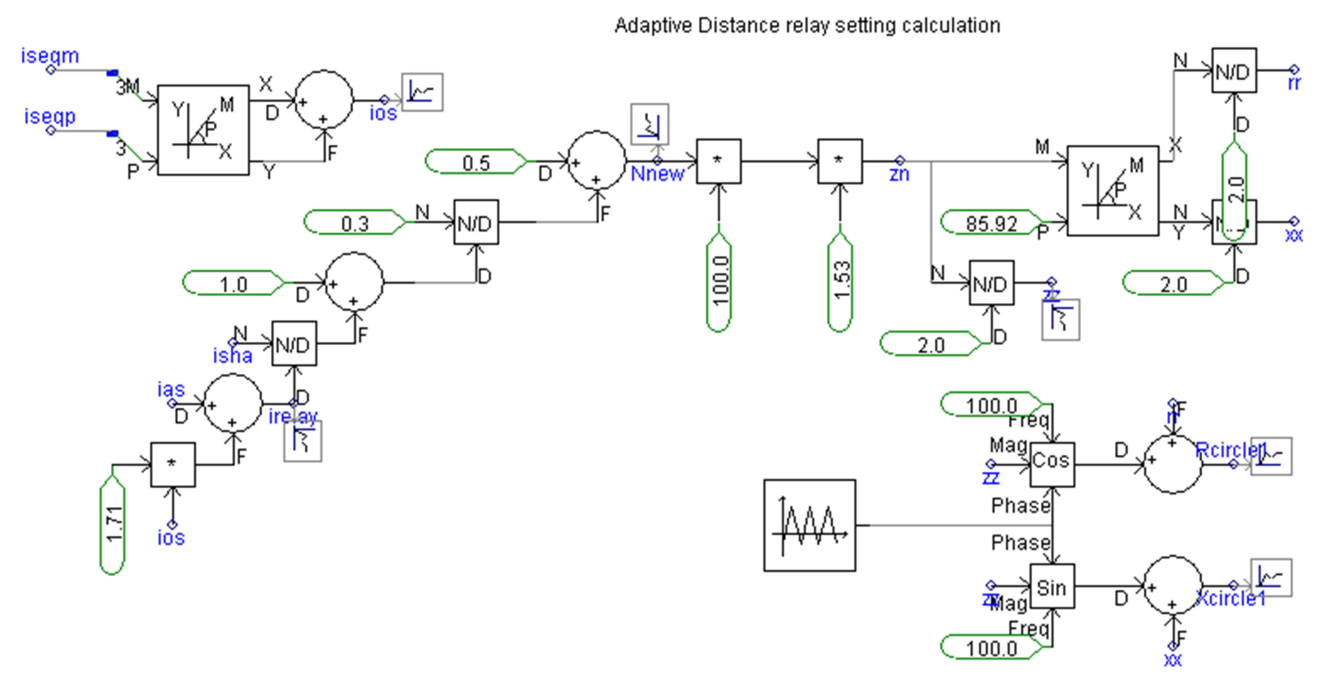

Fig. 3. Adaptive Mho relaying modeling in PSCAD

shunt injected current phasors are used to calculate first zone setting factor. The calculated apparent impedance is compared with the adaptive distance relay reach setting to detect and locate the fault in the first zone of protection in order to issue trip or no trip decision. The proposed algorithm explained is shown in the Fig. 4. The apparent impedance calculation and adaptive distance relay reach setting calculation are processed simultaneously.

\section{Simulation Results}

The performance of the proposed adaptive distance protection is evaluated for study system shown in Fig. 1. The harmonics introduced by the STATCOM is of the order of $n \pm 1$, hence $11^{\text {th }}$ and $13^{\text {th }}$ harmonics it is due to Voltage Source Converter (VSC) of STATCOM. The use of delta winding at VSC side limits the introduction of triplen harmonics into the system. The effect of harmonics can be effectively filtered out by DFT. To analyze and study the various adaptive distance relay settings with different values of compensation and different modes of compensation are considered. STATCOM is inserted by circuit breaker at $0.1 \mathrm{sec}$ into the power system. Fig. 5 shows the adaptive setting factor $x$ characteristics for the compensation during no fault condition. The solid line shows the setting factor variations for inductive compensation of 100 MVAr injected by STATCOM into the system. The Mho relay setting factor $x$ is decreased and have the value 0.7576 p.u. setting. The dash-dot line shows the variations for capacitive compensation of 100 MVAr. The Mho relay setting factor is adaptively increased to value 0.8833 for capacitive compensation. Utilizing the information of setting factor and using equation (22), the adaptive distance protection Mho characteristics are calculated and shown in 


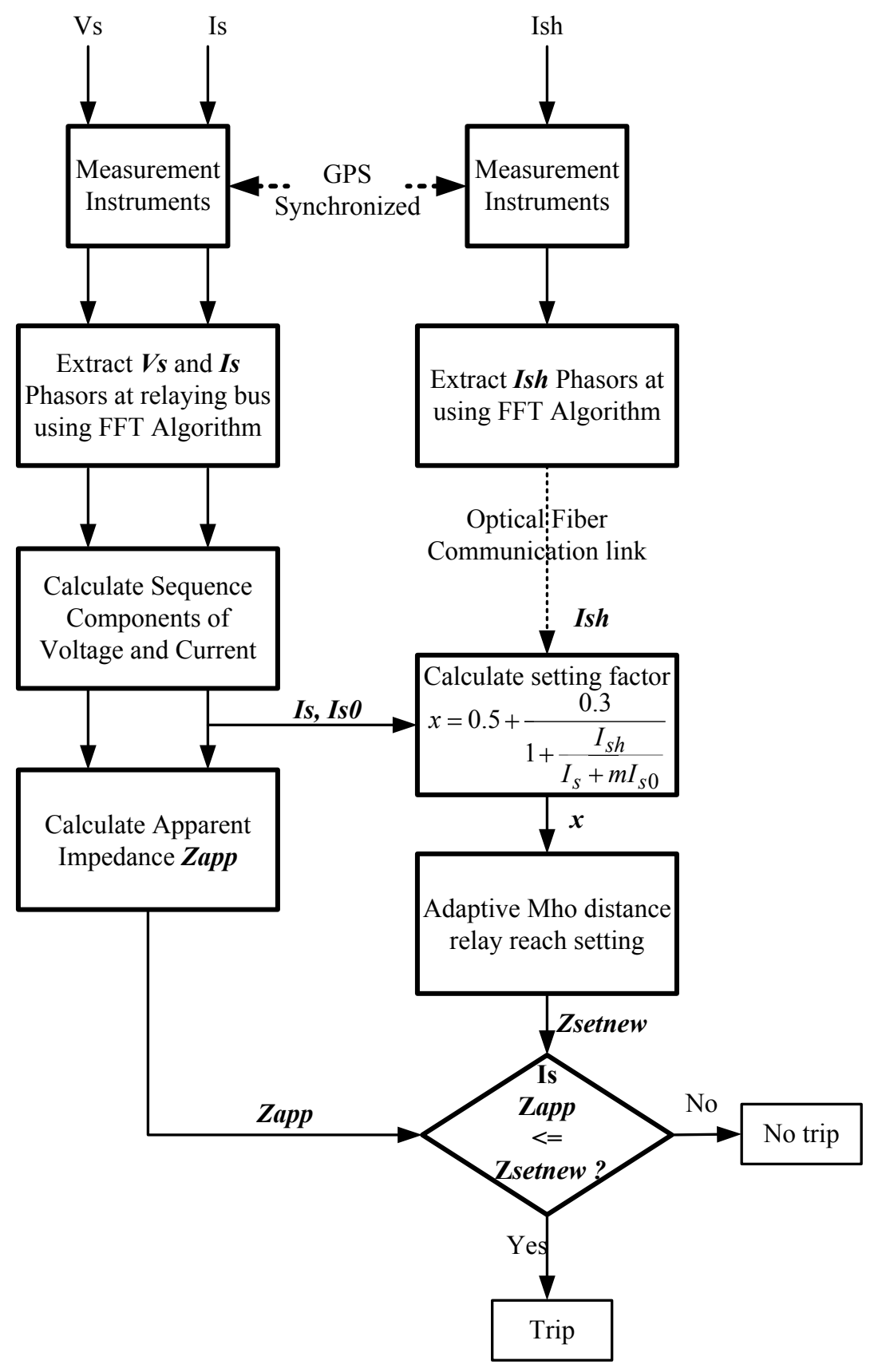

Fig. 4. Adaptive Distance Protection algorithm flow chart

Fig. 6 .

The adaptive distance protection with Mho characteristics is evaluated for various types of faults. Fig. 7 shows fault trajectory response observed for adaptive distance protection and convectional distance protection with $80 \%$ of first zone setting. The fault is introduced at $0.6 \mathrm{sec}$ and fault type is sustained one without fault resistance and with STATCOM. Fig. 8 shows fault trajectory response for BC-g fault with STATCOM. From Fig. 7 and Fig. 8,it is observed that when STATCOM is supplying the capacitive compensation, 


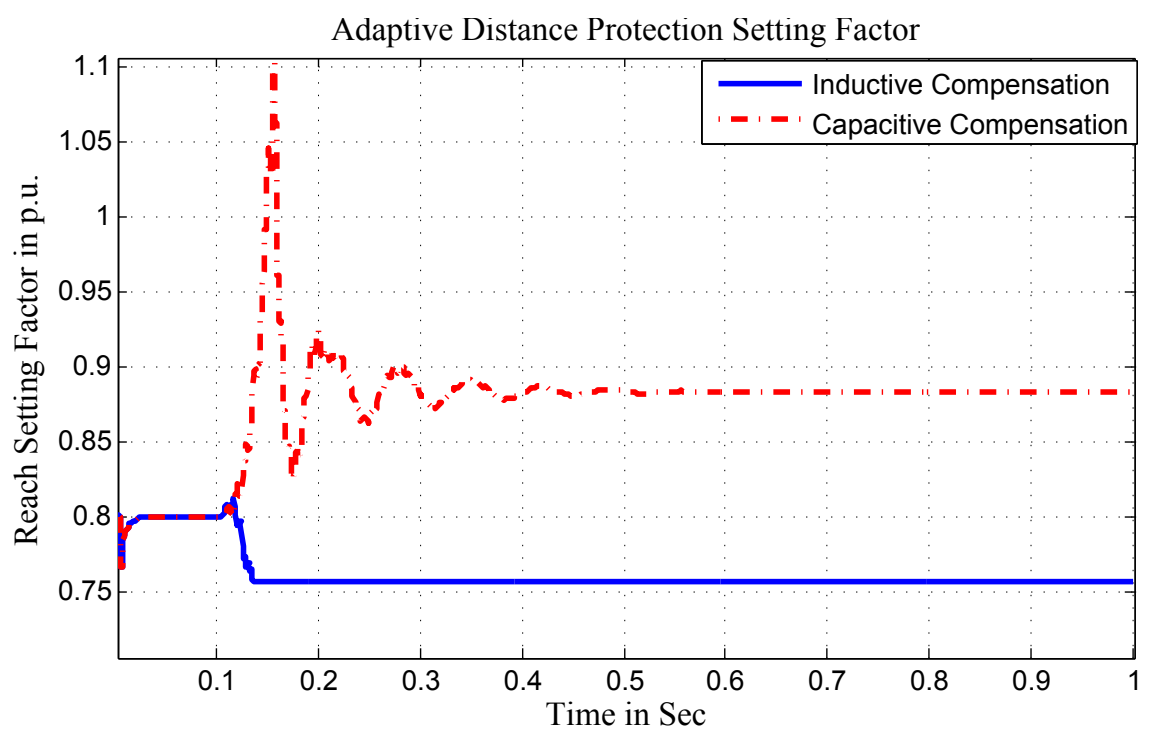

Fig. 5. Adaptive relaying Setting for STATCOM Supplying inductive and capacitive reactive power of $100 \mathrm{MVAr}$

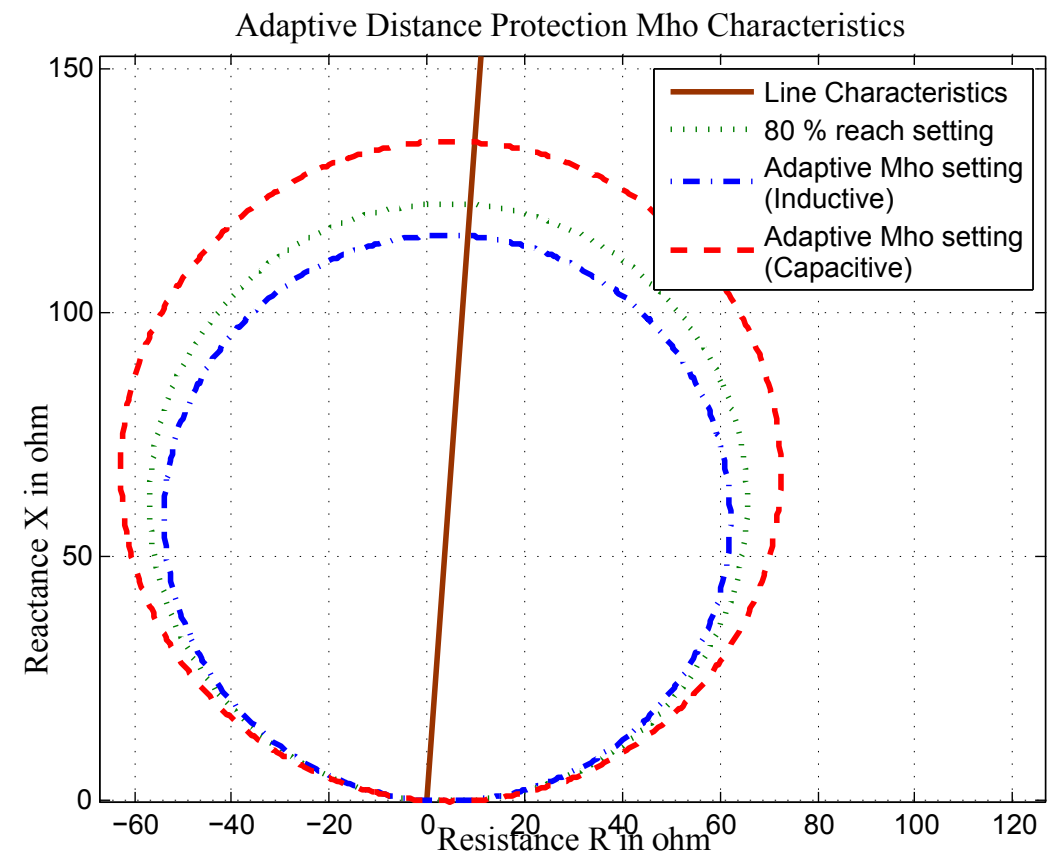

Fig. 6. Adaptive relaying Mho characteristic for injection Inductive and capacitive reactive power of $100 \mathrm{MVAr}$

the adaptive distance protection zone is increased covering more line section to identify and locate the fault point accurately in comparison with normal distance relay with $80 \%$ reach setting. The operating point of fault trajectory is getting settled nearly on the adaptive distance protection Mho characteristics. This proves the accuracy and robustness of adaptive distance protection presented in this paper. The problem of under-reaching the fault point with 


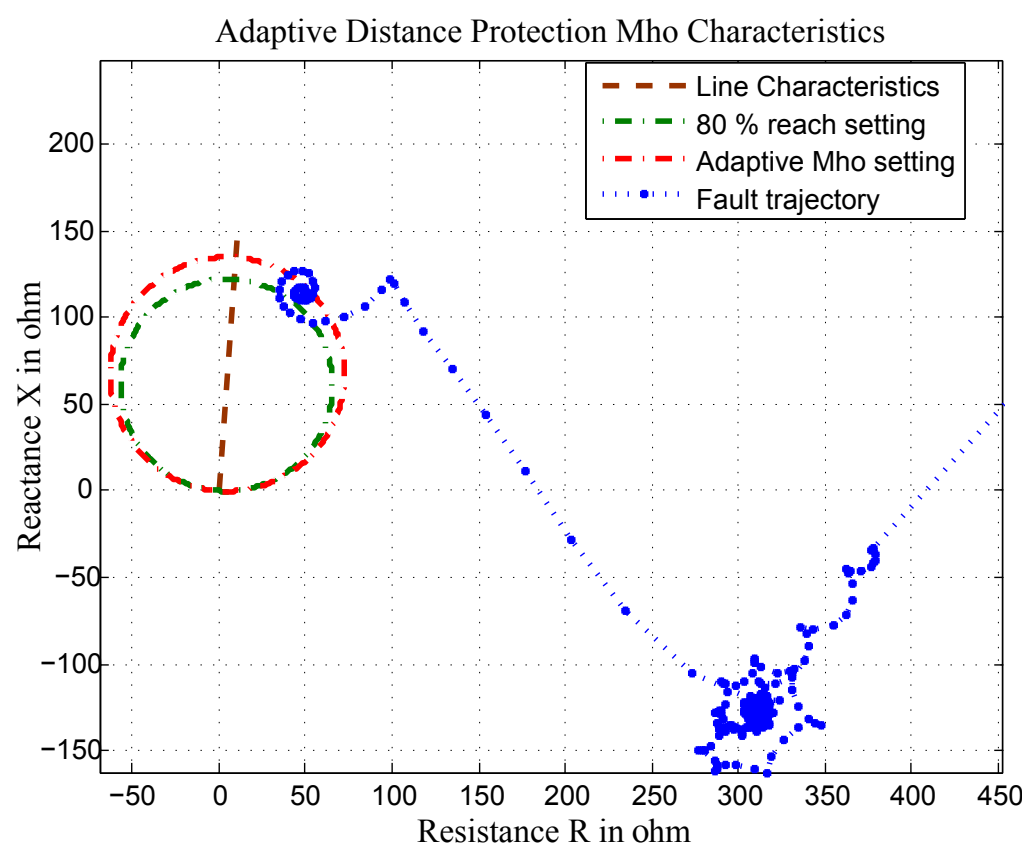

Fig. 7. Response of adaptive distance protection with A-g fault at $80 \%, R_{F}=0$ and 100 MVAr capacitive compensation

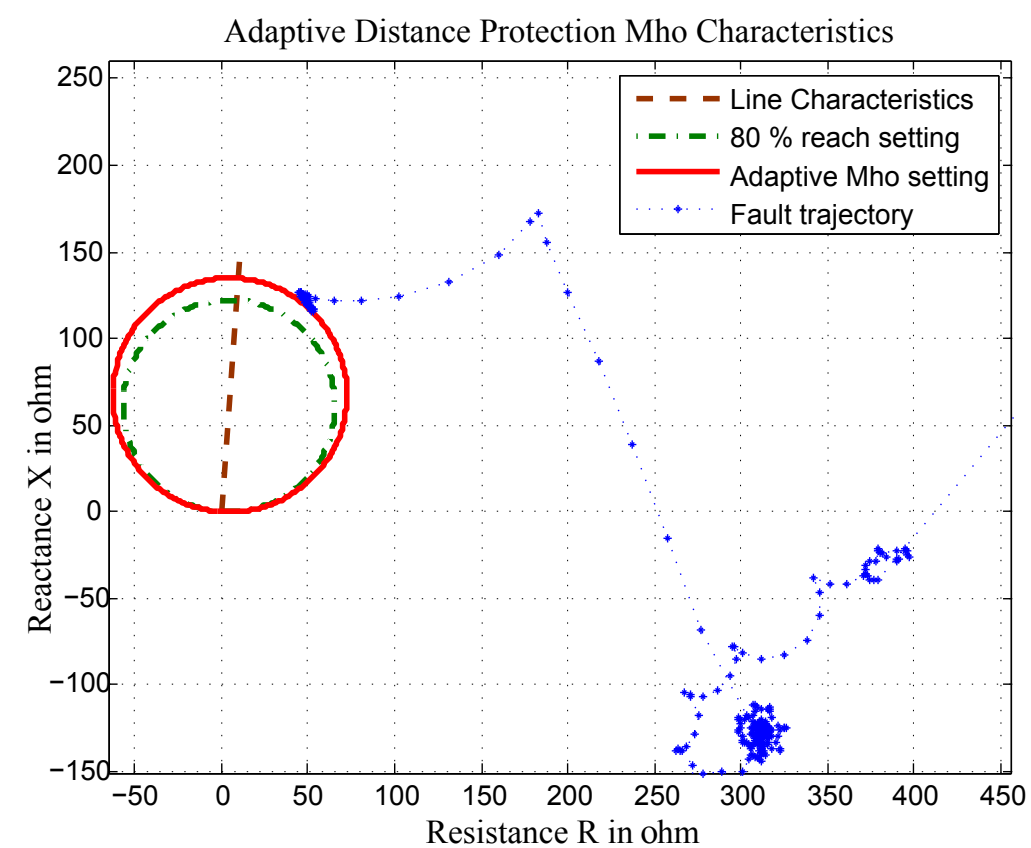

Fig. 8. Response of adaptive distance protection with BC-g fault at $80 \%, R_{F}=0$ and 100 MVAr capacitive compensation

STATCOM is effectively mitigated in the results obtained from simulation. [!h] Fig. 9 show the fault trajectory response for A-g fault at $90 \%$ of line length when compensation is inductive 100 MVAr. Fig. 10 shows the fault trajectory response for $\mathrm{ABC}$ fault at $90 \%$ of the line length. When STATCOM supplies 


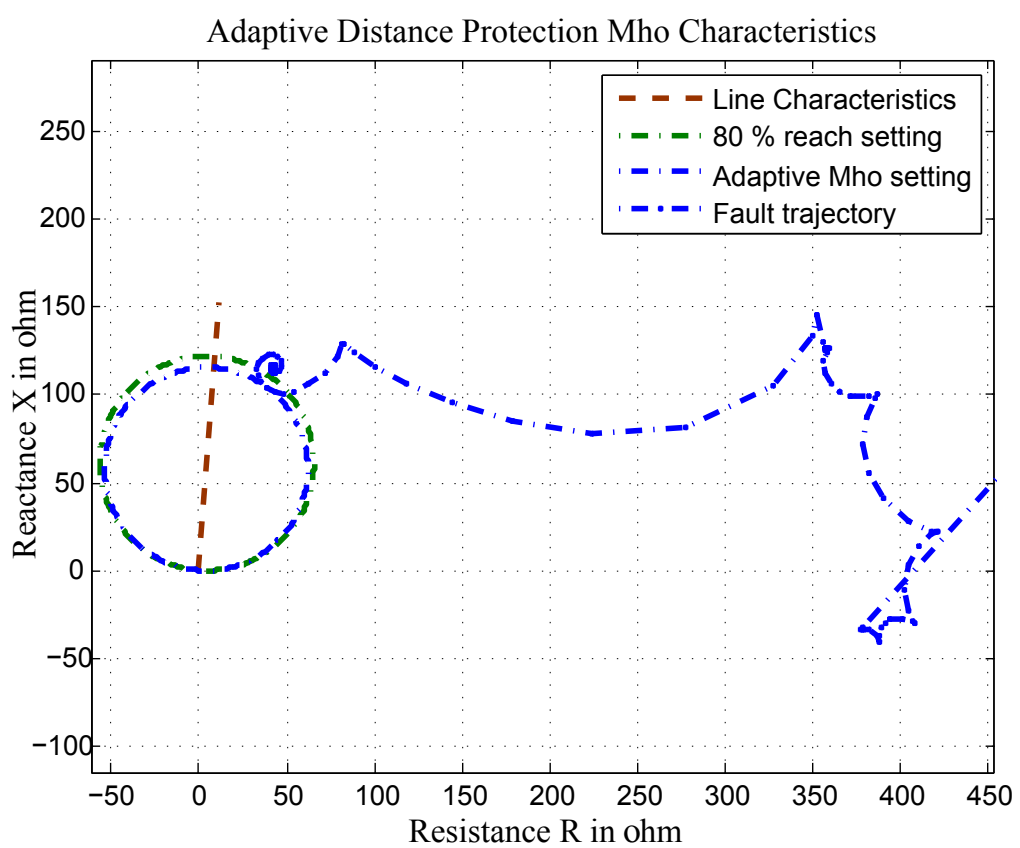

Fig. 9. Response of adaptive distance protection with A-g fault at $90 \%, R_{F}=0$ and 100 MVAr inductive compensation

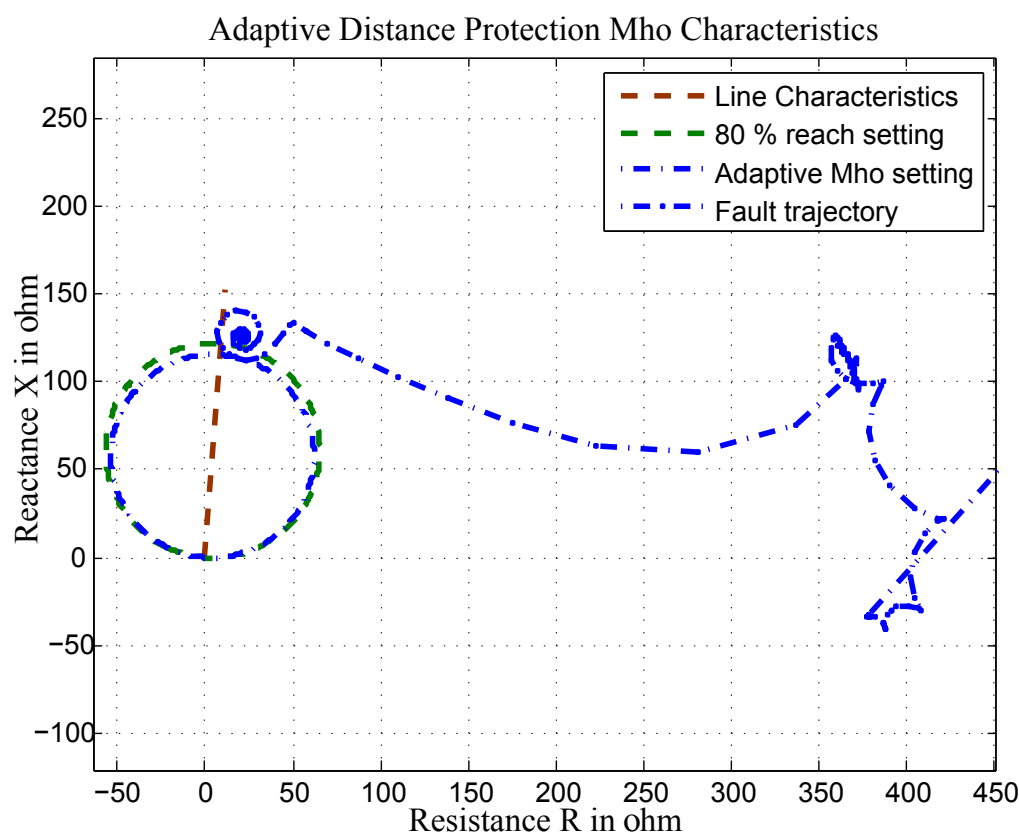

Fig. 10. Response of adaptive distance protection with $\mathrm{ABC}$ fault at $90 \%, R_{F}=0$ and 100 MVAr inductive compensation

inductive compensation, distance relay over-reaches the fault point. As observed from the results Fig. 9 and Fig. 10, the adaptive distance protection first zone reach is decreased, so that it does not issue trip for faults not located in the zone of protection. As observed in the normal distance protection ac- 
commodates the fault trajectory and falsely issues trip with out of zone fault. Adaptive distance protection does not show any mal-operation during inductive compensation as observed form simulation results. Hence it mitigated the issue of over-reaching which is one of the main issues for shunt compensated line.

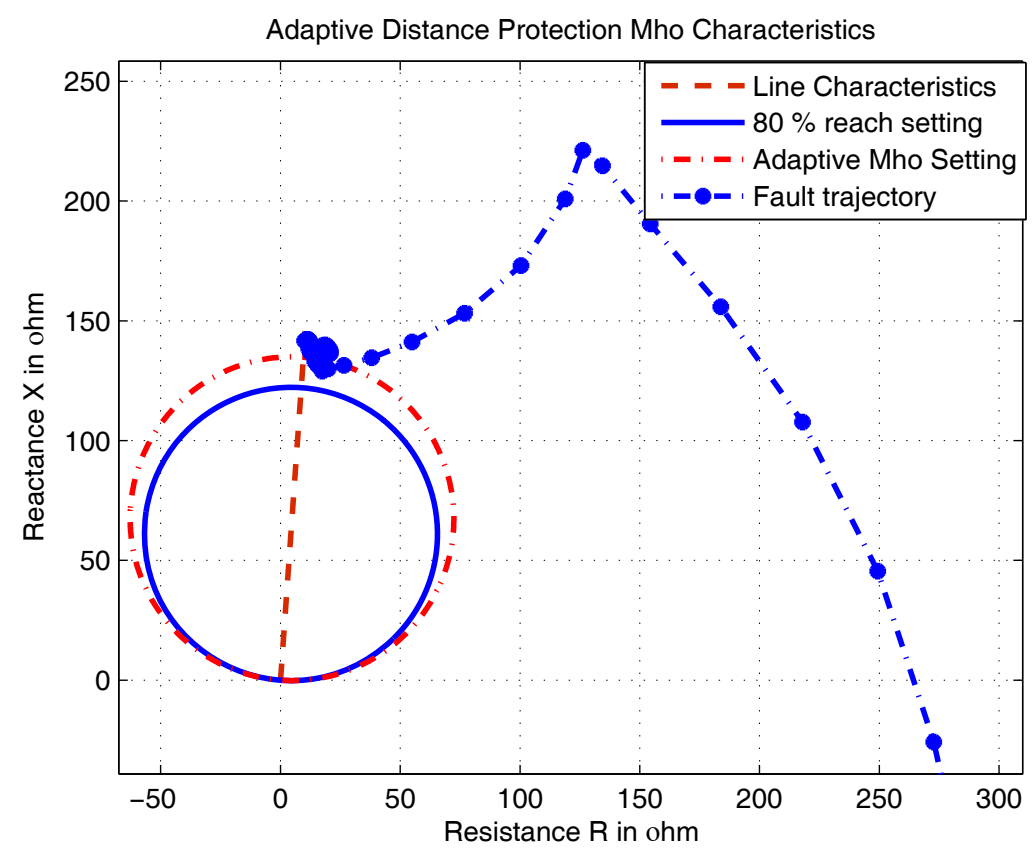

Fig. 11. Response of adaptive distance protection with $\mathrm{AB}$ fault at $80 \%, R_{F}=10$ and 100 MVAr capacitive compensation

Fig. 11 shows the fault trajectory for AB fault for fault at $80 \%$ of line length with $10 \Omega$ fault resistance with 100 MVAr capacitive compensation at midpoint. It is observed that, the adaptive zone setting accurately locates the fault in the zone with compensation. The reach of the Mho circle is increased as per the setting calculated for 100 MVAr capacitive compensation. Similarly, response for adaptive distance protection with AB-g fault at $80 \%$ of line length with $10 \Omega$ fault resistance with 100 MVAr capacitive compensation at mid-point. Hence, it can be concluded that novel adaptive distance protection mentioned in this paper analytically and with simulation results, accurately works for all severe faults.

The proposed algorithm is simulated for several fault conditions with and without fault resistances and results observed are tabulated in Table 1. The results for normal distance relay fault location estimation and adaptive relay fault location with percentage error is shown in table. It is observed form the tabular results that, algorithm have minimum fault distance error of $0.07 \%$ and maximum error of $0.6 \%$. The proposed adaptive relaying algorithm give accurate results for fault with no resistance and as fault resistance increases, the error in fault distance estimation increases. For very high fault resistance, 


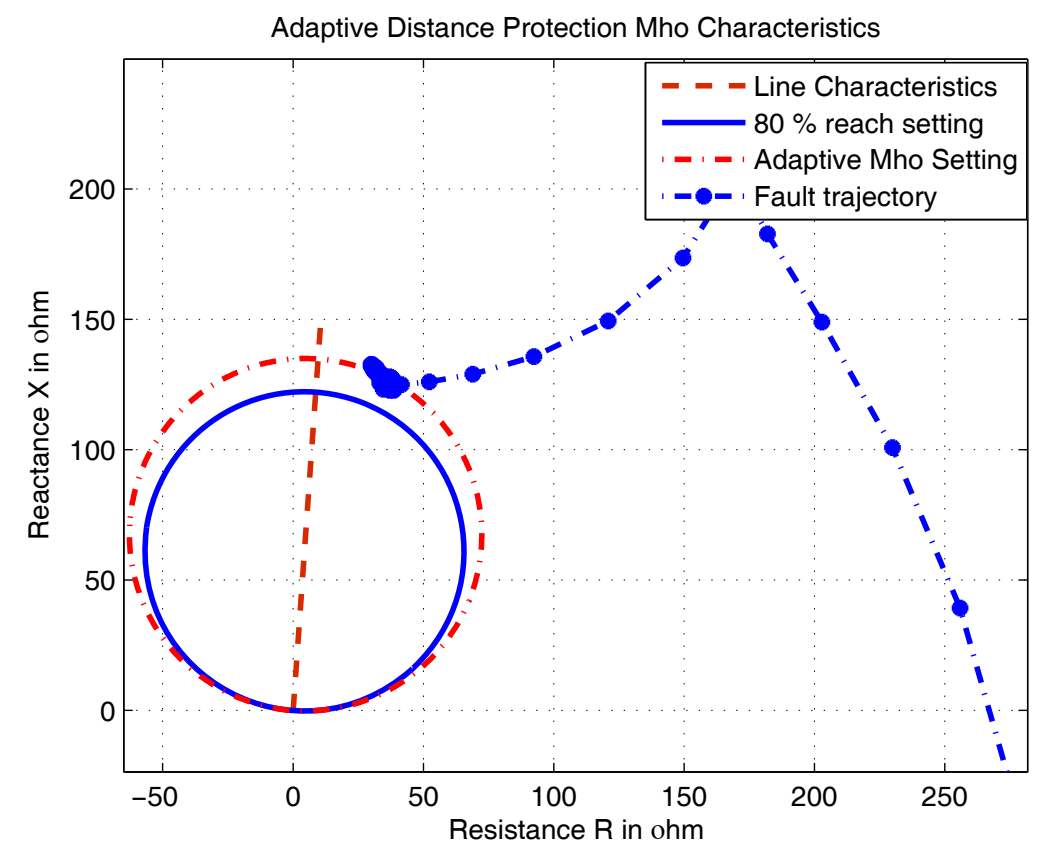

Fig. 12. Response of adaptive distance protection with $\mathrm{AB}$-g fault at $80 \%, R_{F}=10$ and 100 MVAr capacitive compensation

it may locate the fault out of zone.

\section{$7 \quad$ Hardware based validation}

\subsection{Two machine system hardware details}

Two machine system with STATCOM controller hardware setup is shown in Fig. 13 for proposed per phase DIPR algorithm validation. The sending end generator have on-board AVR with shunt DC motor as a prime mover having capacity of $3 \mathrm{~kW}$. The receiving end generator has manual excitation control with VFD induction motor as a prime mover having $2 \mathrm{~kW}$ capacity. STATCOM controller is connected at the mid-point of $200 \mathrm{~km}$ TL. The STATCOM have DSP based closed loop controller to regulate mid-point voltage to 1 p.u. Transmission lines are pi-equivalent models with four section viz., $30 \mathrm{~km}, 70$ $\mathrm{km}, 70 \mathrm{~km}$ and $30 \mathrm{~km}$. CT6841 sensor used for current measurements are HIOKI make. Power analyser 3390 HIOKI make is used as real time data recorder for acquiring current and voltage signals for different fault cases. The real time data recorder have sampling rate of $10 \mathrm{kHz}$ and have four voltage and current channels. Due to the limited number of channels and considering the same time stamping on both end measurements on two phases of each bus are recorded for algorithm validation. The proposed faulty phase detec- 
Table 1

Fault distance estimation for proposed adaptive relaying and normal distance relaying

\begin{tabular}{|c|c|c|c|c|c|}
\hline $\begin{array}{l}\text { Fault } \\
\text { type }\end{array}$ & $\begin{array}{l}\text { Fault } \\
\text { resis- } \\
\text {-tance }\end{array}$ & $\begin{array}{l}\text { fault } \\
\text { distance }\end{array}$ & $\begin{array}{l}\text { Normal } \\
\text { distance relay } \\
\text { fault location }\end{array}$ & $\begin{array}{l}\text { Adaptive } \\
\text { relay } \\
\text { fault location }\end{array}$ & $\begin{array}{l}\% \\
\text { error }\end{array}$ \\
\hline \multirow[t]{3}{*}{ A-g } & 0 & 160 & 164 & 160.50 & 0.17 \\
\hline & 5 & 200 & 208 & 199.80 & -0.07 \\
\hline & 10 & 240 & 256 & 241.30 & 0.43 \\
\hline \multirow[t]{3}{*}{ B-g } & 0 & 160 & 164 & 160.80 & 0.27 \\
\hline & 5 & 200 & 209 & 200.90 & 0.30 \\
\hline & 10 & 240 & 257 & 241.60 & 0.53 \\
\hline \multirow[t]{3}{*}{ C-g } & 0 & 160 & 166 & 160.30 & 0.10 \\
\hline & 5 & 200 & 211 & 201.20 & 0.40 \\
\hline & 10 & 240 & 257 & 239.80 & -0.07 \\
\hline \multirow[t]{3}{*}{ AB-g } & 0 & 160 & 166 & 159.30 & -0.23 \\
\hline & 5 & 200 & 210 & 200.80 & 0.27 \\
\hline & 10 & 240 & 265 & 240.90 & 0.30 \\
\hline \multirow[t]{3}{*}{ BC-g } & 0 & 160 & 163 & 159.80 & -0.20 \\
\hline & 5 & 200 & 210 & 201.30 & 0.43 \\
\hline & 10 & 240 & 266 & 241.80 & 0.60 \\
\hline \multirow[t]{3}{*}{ AC-g } & 0 & 160 & 167 & 159.10 & -0.30 \\
\hline & 5 & 200 & 214 & 200.90 & 0.30 \\
\hline & 10 & 240 & 269 & 239.30 & -0.23 \\
\hline \multirow[t]{3}{*}{$\mathrm{AB}$} & 0 & 160 & 168 & 160.20 & 0.07 \\
\hline & 5 & 200 & 212 & 199.30 & -0.23 \\
\hline & 10 & 240 & 263 & 240.20 & 0.07 \\
\hline \multirow[t]{3}{*}{$\mathrm{BC}$} & 0 & 160 & 168 & 161.10 & 0.37 \\
\hline & 5 & 200 & 209 & 200.40 & 0.13 \\
\hline & 10 & 240 & 259 & 240.60 & 0.20 \\
\hline \multirow[t]{3}{*}{$\mathrm{AC}$} & 0 & 160 & 168 & 160.90 & 0.30 \\
\hline & 5 & 200 & 215 & 200.70 & 0.23 \\
\hline & 10 & 240 & 268 & 241.70 & 0.57 \\
\hline \multirow[t]{3}{*}{$\mathrm{ABC}$} & 0 & 160 & 163 & 160.10 & 0.03 \\
\hline & 5 & 200 & 207 & 200.90 & 0.30 \\
\hline & 10 & 240 & 257 & 241.60 & 0.53 \\
\hline
\end{tabular}

tion algorithm is based on per phase and fault location algorithm requires measurement of all the three phases, hence only faulty phase detection and classification algorithm is validated in hardware. Recorded samples of fault events are fed to MATLAB program which implements the proposed relaying algorithm at $1 \mathrm{kHz}$ after downsampling in offline mode. The recorded samples are used to calculate voltage and current phasors using recursive discrete fourier transform. 


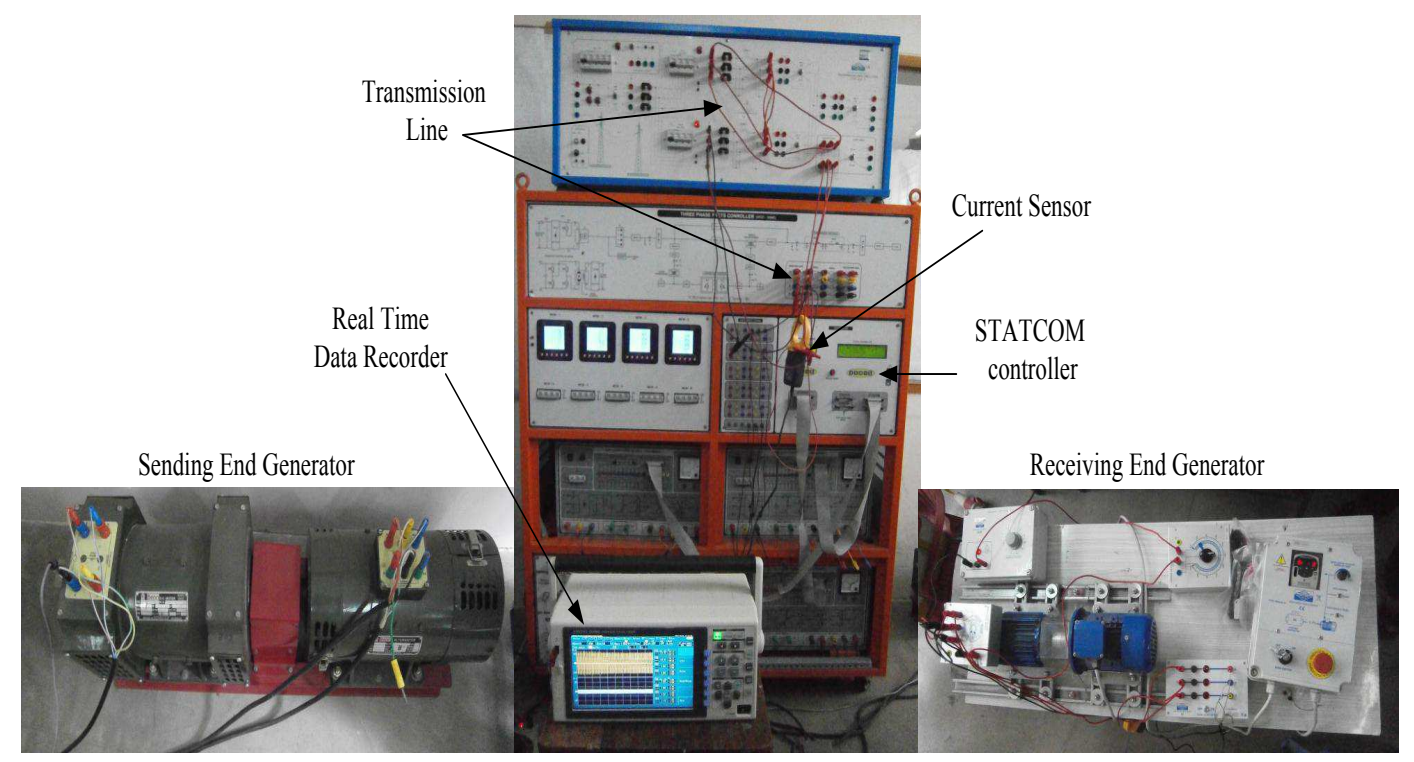

Fig. 13. Two machine system with STATCOM controller hardware setup

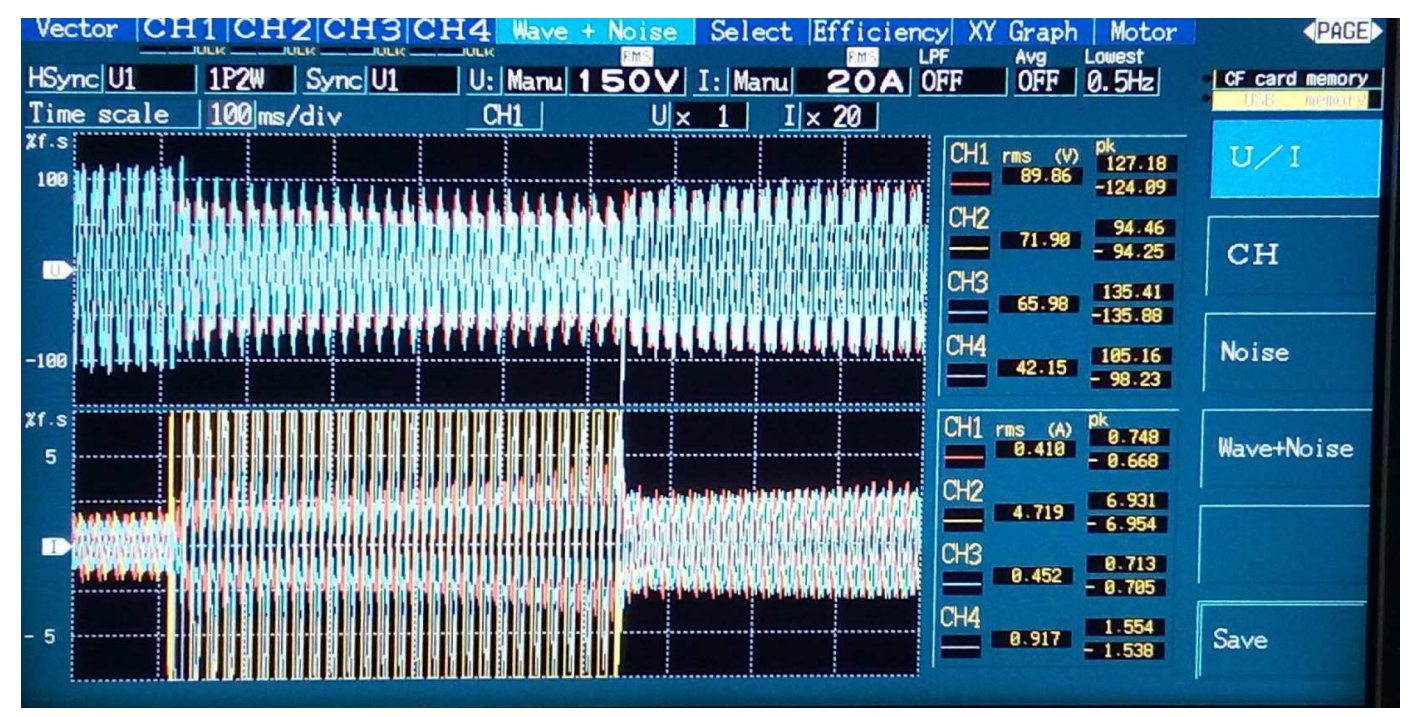

Fig. 14. Real time data recorder waveforms for A-g fault at $30 \mathrm{~km}$ with mid-point STATCOM controller for $0.1 \Omega$ fault resistance

\subsection{Experimental results and discussion}

The parameters for $200 \mathrm{~km}$ pi-equivalent model transmission line hardware setup are $X_{l}=0.16125 \Omega / \mathrm{km}$ and $R_{f}=0.05615 \Omega / \mathrm{km}$. The STATCOM in hardware setup is configured to work in the open-loop control mode to sup-ply either inductive or capacitive compensation. Fig. 14 shows the recorded waveform from real time data recorder for A-g fault at $30 \mathrm{~km}$ TL from sending end generator with mid-point STATCOM controller for $0.1 \Omega$ fault resistance. Due to limited number of channels available for measurement with real time data recorder having 4 voltage channels and 4 current channels, only line to 


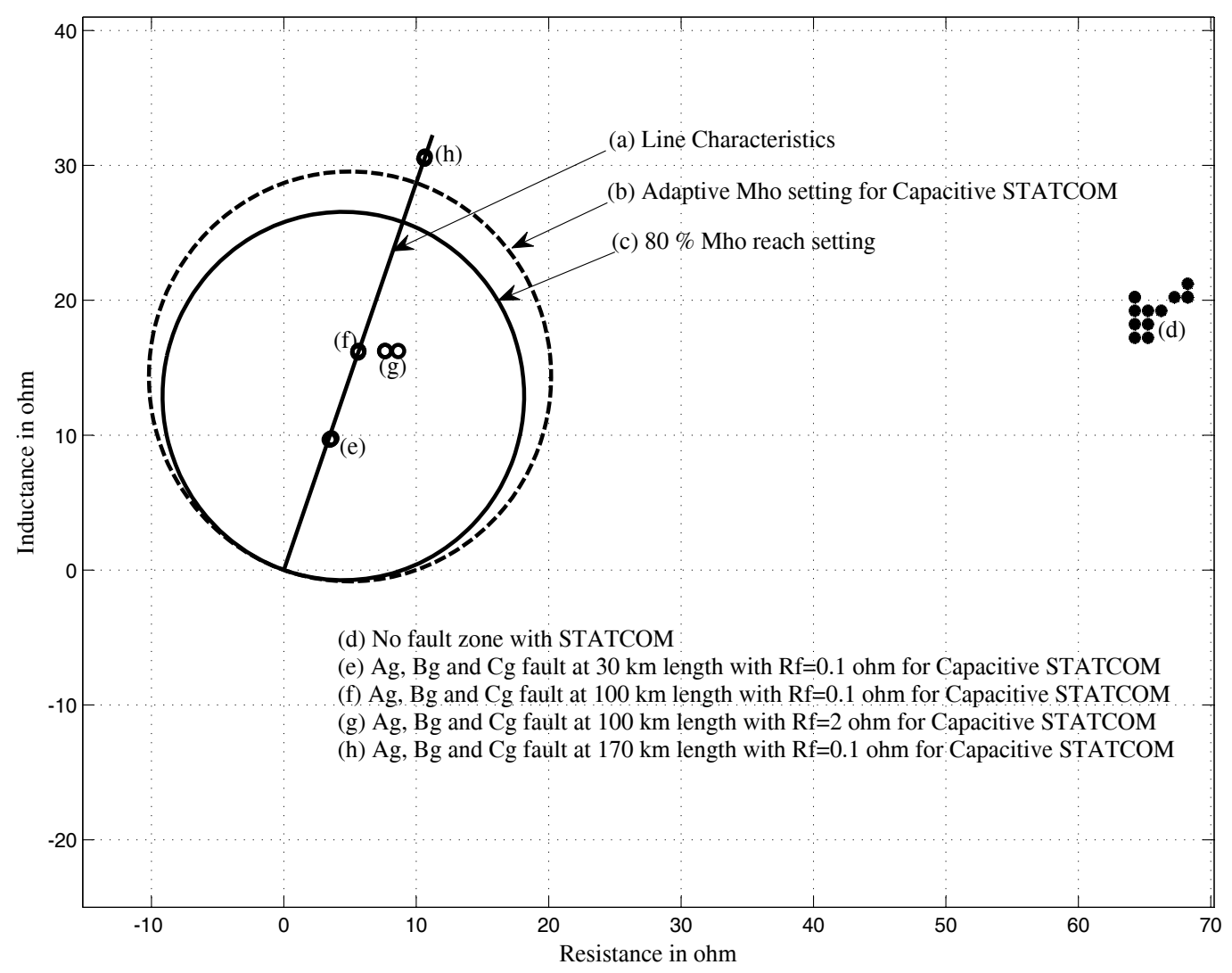

Fig. 15. Hardware results for various line to ground faults with Capacitive STAT$\mathrm{COM}$

ground faults are verified in the hardware results.

More than 200 recorded hardware results are verified for A-g, B-g and C-g faults at $30 \mathrm{~km}, 100 \mathrm{~km}$ and $170 \mathrm{~km}$ of line length. Fig. 15 shows the results for faults with capacitive compensation. In Fig. 15 (a) shows line characteristic, (b) shows adaptive Mho setting calculated from measured value of STATCOM injected current, (c) shows $80 \%$ reach setting of conventional distance relay, (d) shows no fault zone with inductive compensation, (e) shows various line to ground faults at $30 \mathrm{~km}$ of line length with $0.1 \Omega$ fault resistance, (f) shows line to ground faults at $100 \mathrm{~km}$ with $0.1 \Omega$ fault resistance, $(\mathrm{g})$ shows line to ground faults at $100 \mathrm{~km}$ with $2 \Omega$ fault resistance, (h) shows line to ground faults at $170 \mathrm{~km}$ with $0.1 \Omega$ fault resistance. The adaptive Mho setting zone is increased compared with conventional relay to overcome the under-reach of fault points. It is observed that fault points for faults at $170 \mathrm{~km}$ of line length are not located in the adaptive Mho setting zone and it discriminates very accurately.

Fig. 16 shows the results for inductive compensation hardware results. In Fig. 15 (a) shows line characteristic, (b) shows adaptive Mho setting calculated from measured value of STATCOM injected current, (c) shows $80 \%$ reach setting of conventional distance relay, (d) shows no fault zone with inductive 


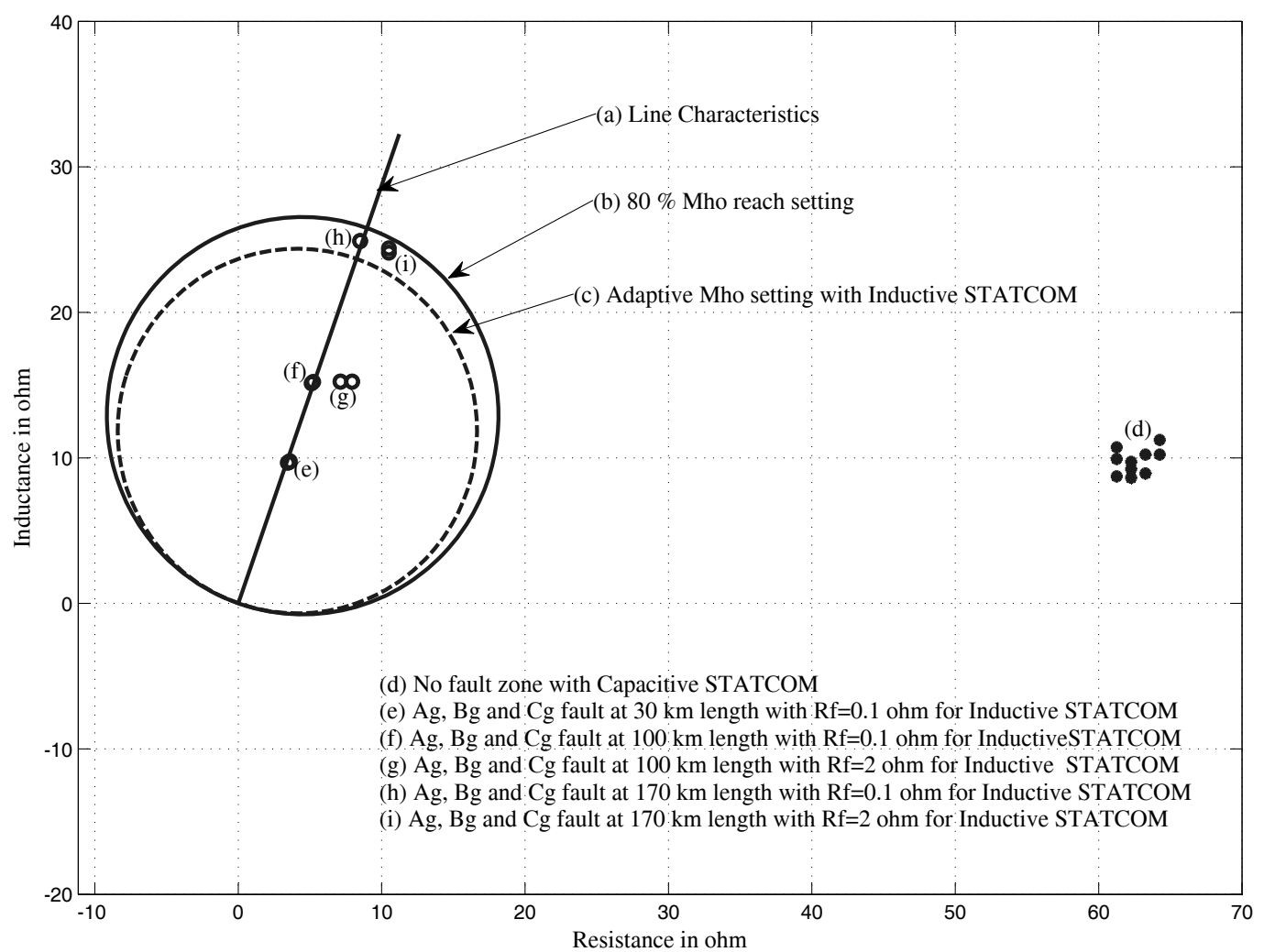

Fig. 16. Hardware results for various line to ground faults with Inductive STATCOM compensation, (e) shows various line to ground faults at $30 \mathrm{~km}$ of line length with $0.1 \Omega$ fault resistance, (f) shows line to ground faults at $100 \mathrm{~km}$ with $0.1 \Omega$ fault resistance, (g) shows line to ground faults at $100 \mathrm{~km}$ with $2 \Omega$ fault resistance, (h) shows line to ground faults at $170 \mathrm{~km}$ with $0.1 \Omega$ fault resistance, (i) shows line to ground faults at $170 \mathrm{~km}$ with $0.1 \Omega$ fault resistance. The adaptive Mho setting zone is decreased compared with conventional relay to overcome the over-reach of fault points. It is observed that fault points for faults at $170 \mathrm{~km}$ of line length are not located in the adaptive Mho setting zone and it discriminates very accurately. Instead, conventional relay mal-operates and locates the $170 \mathrm{~km}$ fault point in its zone. The proposed relaying scheme is having the feature of being adaptive to the compensation of STATCOM which is not available in conventional relay $[8,12,18,23,25,26]$.

\section{Conclusion}

Recursive simulation study is performed to verify the adaptive distance protection performance. It is found that the adaptive distance protection performs better than the normal distance relay for fault occurring near to the boundary of first zone. The faults with less resistance lie in the adaptive zone as reach is increased during capacitive compensation which is usually the case 
during heavy loading conditions. But for high fault resistance, adaptive distance relay may UR to detect fault point which can be overcome by changing relay characteristics with quadrilateral adaptive distance relay characteristics. The adaptive distance protection presented analytically and evaluated by simulations performs better than the normal distance relaying with midpoint STATCOM. Results presented show novelty, accuracy and reliability of the algorithm proposed in this paper with maximum error in distance location is $0.6 \%$. The study demonstrates the necessity for development of other various algorithms using expert technique like ANN, Fuzzy, SVM and Expert system based approach which is underway for extending this work and will be reported in the near future.

\section{References}

[1] Phadke, Arun G., and James S. Thorp. "Computer relaying for power systems". Wiley. com, 2009.

[2] Hingorani, Narain G., and Lazlo Gyugyi. "Understanding FACTS: Concepts and technology of flexible AC transmission systems". NewYork:Wiley, (1999).

[3] Padiyar, K. R. "FACTS Controllers in power transmission and distribution". New Age International, 2007.

[4] Johns, Allan T. and Song Yong Hua. "Flexible AC transmissions systems (FACTS)", (1999).

[5] S. A. Soman., Power system protection a web course on nptel available online on IIT Bombay website.

[6] Kazemi, A., S. Jamali, and H. Shateri. "Effects of STATCOM on distance relay tripping characteristic." In Transmission and Distribution Conference and Exhibition: Asia and Pacific, 2005 IEEE/PES, pp. 1-6. IEEE, 2005.

[7] Khederzadeh, Mojtaba. "The impact of FACTS device on digital multifunctional protective relays." In Transmission and Distribution Conference and Exhibition 2002: Asia Pacific. IEEE/PES, vol. 3, pp. 2043-2048. IEEE, 2002.

[8] Albasri, Fadhel A., T. S. Sidhu, and Rajiv K. Varma. "Impact of shunt-FACTS on distance protection of transmission lines." In Power Systems Conference: Advanced Metering, Protection, Control, Communication, and Distributed Resources, 2006. PS'06, pp. 249-256. IEEE, 2006.

[9] Albasri, Fadhel A., Tarlochan Singh Sidhu, and Rajiv K. Varma. "Performance comparison of distance protection schemes for shunt-FACTS compensated transmission lines." , IEEE Transactions on Power Delivery vol-22, no. 4 (2007): 2116-2125. 
[10] Singh, Arvind R., Azhar Ahmed, and Sanjay Dambhare. "Robust distance protection of mid-point shunt compensated transmission line." In Power India Conference, 2012 IEEE Fifth, pp. 1-5. IEEE, 2012.

[11] Albasri, Fadhel A., T. S. Sidhu, and Rajiv K. Varma. "Mitigation of adverse effects of midpoint shunt-FACTS compensated transmission lines on distance protection schemes." In Power Engineering Society General Meeting, 2007. IEEE, pp. 1-8. IEEE, 2007.

[12] Sadeh, Javad. "A Novel Communication Aided Approach for Protection of Shunt Compensated Transmission Lines." Journal of Mathematics (2010).

[13] Kazemi, A., S. Jamali, and H. Shateri. "Adaptive distance protection in presence of STATCOM on a transmission line." In Transmission and Distribution Conference and Exposition, 2010 IEEE PES, pp. 1-6. IEEE, 2010.

[14] Adamiak, M. G., A. P. Apostolov, M. M. Begovic, C. F. Henville, K. E. Martin, G. L. Michel, A. G. Phadke, and J. S. Thorp. "Wide area protection technology and infrastructures." Power Delivery, IEEE Transactions on 21, no. 2 (2006): 601-609.

[15] IEEE Standard for Synchrophasors for Power Systems, "IEEE Std C37.118-2005 (Revision of IEEE Std 1344-1995), vol., no., pp.0-1,57, 2006.

[16] Dambhare, S.; Soman, S.A.; Chandorkar, M.C., "Adaptive Current Differential Protection Schemes for Transmission-Line Protection" Power Delivery, IEEE Transactions on , vol.24, no.4, pp.1832,1841, Oct. 2009.

[17] Gupta, Om Hari and Manoj Tripathy, "An Innovative Pilot Relaying Scheme for Shunt Compensated Line" Power Delivery, IEEE Transactions on , vol.PP, no.99, pp.1,1.

[18] Manori, Ashok, Manoj Tripathy, and Hari Om Gupta. "Advance Compensated Mho Relay Algorithm for a Transmission System with Shunt Flexible AC Transmission System Device." Electric Power Components and Systems 42.16 (2014): 1802-1810.

[19] Manitoba HVDC Research Centre,PSCAD Users Guide V4.2.

[20] Ghosh, Debomita, T. Ghose and D. K. Mohanta "Communication feasibility analysis for smart grid with phasor measurement units" Industrial Informatics, IEEE Transactions on 9.3 (2013): 1486-1496.

[21] Singh, Arvind R., and Sanjay S. Dambhare. "Adaptive distance protection of transmission line in presence of SVC." International Journal of Electrical Power \& Energy Systems 53 (2013): 78-84.

[22] Singh, Arvind R., Nita R. Patne, and Vijay S. Kale. "Adaptive distance protection setting in presence of mid-point STATCOM using synchronized measurement." International Journal of Electrical Power \& Energy Systems 67 (2015): 252-260. 
[23] Wen, Minghao, Deshu Chen, and Xianggen Yin. "A novel fast distance relay for long transmission lines." International Journal of Electrical Power \& Energy Systems 63 (2014): 681-686.

[24] Dash, P. K., A. K. Pradhan, and G. Panda. "Apparent impedance calculations for distance-protected transmission lines employing series-connected FACTS devices." Electric Power Components and Systems 29.7 (2001): 577-595.

[25] Bhalja, Bhavesh, and R. P. Maheshwari. "Trends in Adaptive Distance Protection of Multiterminal and Double-Circuit Lines." Electric Power Components and Systems 34.6 (2006): 603-617.

[26] Singh, Arvind, Nita Patne, Vijay Kale, and Piyush Khadke. "Digital Impedance Pilot Relaying Scheme for STATCOM Compensated Transmission Line for fault phase classification with fault location." IET Generation, Transmission \& Distribution 11(10) (2017): 25862598. 